\title{
Convex Phillips Curve Explaining Openness and Inflation Nexus
}

\author{
S. Ali Shah Syed ${ }^{*}$, Helène Syed Zwick ${ }^{2,3}$ \\ ${ }^{1}$ American University in Cairo, Egypt \\ ${ }^{2}$ Confrontations Europe, 227 bd Saint Germain, Paris, France \\ ${ }^{3}$ University of Lille 1, LEM (UMR-CNRS 9221), Lille, France \\ Email: "Sas.syed@aucegypt.edu, Helene.zwick@orange.fr
}

Received 24 November 2015; accepted 20 December 2015; published 23 December 2015

Copyright (C) 2015 by authors and Scientific Research Publishing Inc.

This work is licensed under the Creative Commons Attribution International License (CC BY). http://creativecommons.org/licenses/by/4.0/

(c) (i) Open Access

\section{Abstract}

We study the theoretical nexus between inflation and trade openness in the presence of a non-linear Phillips curve. Phillips curve explains the inverse relationship between unemployment and inflation; however, the open economy macroeconomic models usually propose that the slope of the trade-off should be related to the extent of trade openness. The role of openness as a check on inflation has recently attracted attention of many [1]. The parallelism between the recent globalization wave and the fall in inflation has led to a perception that the determinants of the slowdown in inflation were not only the domestic ones but could partly be due to increased trade openness. This study describes this relationship considering a non-linear Phillips curve. Using the conventional Phillips curve approximated by Cobb-Douglas model we confirm the earlier observations regarding the existence of a significant impact of openness on inflation. The interesting contribution of this study is not only to establish the trade-openness and inflation nexus but also to identify the relevant channels through which openness impacts inflation. Our model predicts that in the current scenario of increased openness a non-linear symmetric loss function may still prevail, but for the policy purposes it necessitates to consider domestic and foreign propensities to import and the exchange rate sensitivity to inflation. In addition, the integration of the international markets would result into an even more important role of exchange rate dynamics as a response to the rising international trade. We find that in the presence of a convex Phillips curve any upward variation in the foreigners' propensity to import would place a downward pressure on domestic inflation, provided that the current and the lagged rate of unemployment are less than minimum unemployment rate. Our model, while assessing the short run dynamics, also suggests that increased openness results into a complex divide among different economies, due to their sizes and structures. Investigating such a relationship as an extension of this study for different economic groups could reveal further interesting facts.

"Corresponding author. 


\section{Keywords}

\section{Globalization, Import Prices, Trade Openness, Inflation, Phillips Curve}

\section{Introduction}

The changed environment of reduced trade barriers in the international trade has posed new challenges to the contemporary monetary policies of the central banks and places doubts on the credibility and effectiveness of the monetary policy. With the increased level of globalization, inflation in different economies has witnessed unanticipated changes and it is questionable that whether despite the increasing acceptance of the inflation targeting strategies, it is the inflation bias or the unanticipated and miscalculated endogenous factors effecting the domestic inflation unexpectedly. Besides others, globalization has been considered as one of the important forces behind these unanticipated variations in inflation and between the inflation-output gap relationships. If increased openness could affect domestic inflation and the dynamics of domestic inflation process, this will place an important question on the relevancy of the central banks' monetary policy to check inflation. Although it is established among the economists that the long run inflation is a monetary phenomenon and is controlled by the central bank, the short run fluctuations in inflation are attributed to various factors, including the nonmonetary factors as well.

There is rich literature on the determination of these factors and a negative impact of greater openness on inflation has been established [1]-[4]. This observation has been retrieved by various empirical studies based on the augmented Phillips curve, as it is customary to rely on Phillips analysis to observe the relationship between inflation and unemployment or output gap. However, the conjecture of Phillips that the lower unemployment would lead to higher inflation has been questioned in the recent era. In fact, it has been found that currently inflation has become less responsive to the fluctuations in output and unemployment [5]. This observation signals a flattening of the Phillips curve.

The rationale behind this flattening of the Phillips curve is the price rigidities and real disturbances in explaining macroeconomic fluctuations on the one hand while imperfect the asymmetric information to central banks on the other hand. It is said that the central bank is imperfectly informed regarding real developments in the economy, and hence is continually trying to surmise the state of the economy while simultaneously affecting it [6].

Another argument for this flattening of the Phillips curve is that in fact the sticky prices and wage rigidity result in the short term trade-off between output and inflation as in the other case, if the nominal prices and wages were flexible, it would be a classical dichotomy where the monetary policy would be highly effective in controlling inflation but would have nothing to do with output volatility. However, the slope of this trade off where on one hand could be the institutional aspect of wage-setting mechanism. Beaudry and Doyle [6] could be supposedly related to the average rate of inflation. Ball, Mankiw and Romer [7] provide the evidence that the short run trade-off was flatter in low inflation countries than in high inflation ones. Phillips curves may be flatter when the inflation rate is low, as in times of low inflation the prices would be less responsive to the output fluctuations; however, it might not always be true [8]. Despite a voluminous literature on the issue the puzzle requires some more pieces so as to be completed.

The argument of flattening of the Phillips curve requires revisiting the inflation persistence as well ${ }^{1}$. Currently it has been observed that inflation is getting less persistent [9]. Now, as a conventional Phillips curve equation reveals that inflation depends on its own past and unemployment gap or output gap. In some recent studies weakness has been observed in this tradeoff [10] [11], which points out to the flattening of the Phillips curve. The reasons behind this flattening of Phillips curve are important both from the academia and the policy makers' point of view. One reason for this changing pattern of inflation process could be the inflationary persistence [12], where in the past the trend inflation was not anchored so as the inflation expectations. However, the recent anc-

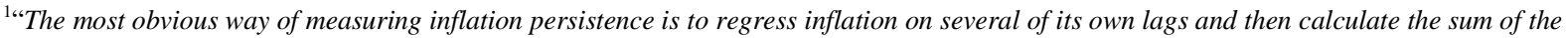
coefficients on lagged inflation. If the sum of the coefficients is close to 1.0, then shocks to inflation have long lived effects on inflation. In other words, inflation behaves like a random walk, so that when inflation goes up, it stays up. If the sum of the coefficients drops well below 1.0, then a shock to inflation has only a temporary effect on inflation, and inflation soon reverts back to its trend level”, Mishkin (2007) [12].
} 
horing of trend inflation resulted in a fall of inflation persistence.

Another reason behind the reduced dependence of inflation on the output gap changes could be the effect of globalization [13] [14]. It means that in the recent wave of reduced trade barriers and increased international trade could desensitize the domestic inflation from the impacts of over or under-heating of the domestic economy to a greater extent. As currently there is a greater role of international factors impacting the domestic inflation, this fact has serious consequences for the monetary policy; 1 ) as the policy makers would not need any more to indulge into a speed limit policy, whatever the magnitude of rise in output be; and 2) that the low level of unemployment as a consequence would be less inflationary.

However, as Mishkin [12], observe that the debate so far on the issue of a less responsive inflation to the economic activity was based on mere correlations and not on the true structural relationships. And in the support yet another opinion that the short-run inflation — unemployment trade off may be driven by a convex Phillips curve [15]. This does not refute the earlier argument of the external factors' impact that makes inflation less sensitive to the variations in the domestic output gap; rather it is the structure, size and strength of economies that figure out this difference. The more an economy is stronger, the more is the inflation sensitivity to the domestic factors. It is said that over the last few years short run Phillips curve remained nonlinear [16] [17] that is a rise in inflation results in a greater decline in unemployment at high unemployment levels than it does when unemployment is already at low levels. Here by nonlinearity we mean convex and not a concave Phillips curve. As a consequence of this convex Phillips curve the NAIRU (non-accelerating inflation rate of unemployment) retains a deterministic rather than a random setting [15].

Through the survey of relevant literature we observe that the consideration remained either to derive the shape of Phillips curve [15] [18] or to study the impact of globalization on the Phillips curve or inflation in the perspective of a linear or flatter Phillips curve [5] [13]. This leaves the lacuna to study the impact of openness in the presence of a convex Phillips curve, and the analysis of this curb is the subject matter and main contribution of this study. In this paper, the objective is not just to replicate the impact of increased openness on inflation, but to go a step further to investigate the response of inflation to openness provided that the Phillips curve is not anymore flat. This is a unique contribution of this study, as to our knowledge globalization inflation relationship has not yet been studied this way.

This paper is organized as follows. The following section describes the convexity of Phillips Curve, while section 3 presents the globalization response to non-linear Phillips Curve and develops the slope of Phillips Curve. Section 4 describes the inflation response to globalization. The last section concludes.

\section{Convexity of the Phillips Curve}

The relationship between unemployment and inflation opened a new chapter in the field of macroeconomics; however in its micro-foundations it describes a simple and visible trade-off. In a scenario of downward rigidity of wages, high rate of unemployment offers an incentive to the firms to lower the wages; which they would not be able to do otherwise over a period of low unemployment. Rather during a period of low unemployment would result in disproportionately high rises in the wages [19]. A simple linear Phillips curve presents this relationship as the following equation:

$$
\pi_{t}=\pi_{t}^{e}+\gamma\left(u_{\text {gap }}\right)+\varepsilon_{t}
$$

where $\pi_{t}$ is the actual inflation, $\pi_{t}^{e}$ is the inflation expectations and the term $\gamma\left(u_{g a p}\right)$ represents the constant slope of the Phillips curve, in the inflation and unemployment gap relationship. The term $\varepsilon_{t}$ is the random disturbance term with a zero mean and constant variance, including the unusual factors that could affect inflation at different moments ${ }^{2}$ but not explained by the explanatory variables.

However, as per the subject matter of this paper, we adopt the slope of a nonlinear or more specifically convex Phillips curve as per Tambakis [15], similar to that of the Debelle and Laxton [20] and Laxton, Rose and Tambakis [21]:

$$
\pi_{t}=\pi_{t}^{e}+\gamma \frac{u^{N}-u_{t}}{u_{t}-\varphi}-\varepsilon_{t}
$$

where $\pi_{t}, \pi_{t}^{e}$ and $\varepsilon_{t}$ are the same as defined in Equation (1); however, $u^{N}$ is the natural rate of unem-

\footnotetext{
${ }^{2}$ These factors may include the external shock (oil price hikes), and the exogenous wage variations.
} 
ployment; $u_{t}$ is the actual rate of unemployment, the term $\varphi$ is the minimum unemployment and $\gamma$ represents the horizontal asymptote defining the maximum unanticipated deflation if excess supply becomes unbounded.

The convexity of the Phillips curve implies that the average unemployment rate consistent with nonaccelerating inflation in a stochastic setting exceeds its deterministic counterpart $u^{N}$ and it denies the impartiality of inflation from the exogenous shocks. It implies that any stochastic shock to the economy consequently fluctuating inflation would lead to a variation in unemployment from its natural rate. According to Tambakis [15], differentiating the Equation (2) explains the original Phillips curve's claim that if the unemployment rate goes below its natural rate, the cost push inflation would grow more than it would grow if the unemployment rate falls at high levels. Such as:

$$
\frac{\partial u_{t}}{\partial \pi_{t}}=-\frac{\left(u_{t}-\varphi\right)^{2}}{\gamma\left(u^{N}-\varphi\right)}<0 .
$$

This traces back the issue to the original Phillips curve conditions; however, as per scope of this study one important observation is that in the literature this habitude of Phillips curve has not been discussed in the context of recent economic up and downs due to the globalization strategy.

\section{Globalization Response to Non Linear Phillips Curve}

Taking into account the liberalization and deregulation of markets [22], the international competition leading to higher productivity growth, an increased labor supply and the resulting check on wage pressures [14], sound fiscal policies [23] and the improved governance of monetary authorities [24], one can depict several factors that may have led to the fall of inflation across countries. Such trends thus reinforce the links between openness and inflation that were notably exhibited by Romer [1] and Lane [25].

Although literature is rich on the relationship between globalization and inflation, it is silent when the question comes to the existence of the same relationship in the presence of a non-linear (convex) Phillips curve. In this regard, we take the Cobb-Douglas approximation as used by Daniels and Van Hoose [26]:

$$
y=\mu\left(p^{*}+s-p\right)+(1-\beta) y+\beta^{*} y^{*}
$$

where the fraction $\beta$ is the domestic and $\beta^{*}$ is the foreign propensity to import; $p$ is the log of aggregate domestic and $p^{*}$ is the foreign price level. While $y$ is the log of aggregate domestic, $y^{*}$ is the foreign output. Finally, $\mu$ is the real exchange rate elasticity of the desired spending.

As the above equation is based on the variables at log level, therefore to get a growth rate we take the first difference of the variables:

$$
y-y_{-1}=\mu\left(p^{*}-p_{-1}^{*}+s-s_{-1}-p+p_{-1}\right)+(1-\beta)\left(y-y_{-1}\right)+\beta^{*}\left(y^{*}-y_{-1}^{*}\right) .
$$

With $p^{\cdot}=\pi_{t}$ it can be written as:

$$
y \cdot \beta]=\mu\left(\pi_{t}^{*}+s_{t}-\pi_{t}\right)+\beta^{*} y^{*} .
$$

Equation (5) shows a Cobb-Douglas form model. However, to take into account the impact of unemployment, we assume a short-term production function of the type given in Daniels and VanHoose [26], where labor is the only factor of production:

$$
y=\alpha l \text {. }
$$

Here unemployment can be stated as the difference of population with the employed labor force:

$$
u=1-l \text {. }
$$

Replacing $l$ with the value in the preceding equation, simplifying and taking the lag:

$$
y_{t-1}=\alpha\left(1-u_{t-1}\right) \text {. }
$$

Now taking the first difference:

$$
y_{t}=-\alpha u_{t} .
$$

Replacing $y_{t}$ from Equation (5) in Equation (4): 


$$
u_{t}=-\frac{\mu}{\alpha \beta}\left(\pi_{t}^{*}+s_{t}^{\cdot}-\pi_{t}\right)-y_{t}^{* *} \frac{\beta^{*}}{\alpha \beta} .
$$

As Equation (5) is also in a level form, so we convert it to first difference. Therefore the lag of Equation (5):

$$
\pi_{t-1}=\pi_{t-1}^{e}+\gamma \frac{u^{N}-u_{t-1}}{u_{t}-\varphi}-\varepsilon_{t-1}
$$

Taking the first difference of the Equation (5):

$$
\pi_{t}^{\cdot}=\pi_{t}^{e}+\gamma\left[\frac{u^{N}-u_{t}}{u_{t}-\varphi}-\frac{u^{N}-u_{t-1}}{u_{t-1}-\varphi}\right]-\varepsilon_{t} .
$$

Suppose

$$
\left[\frac{u^{N}-u_{t}}{u_{t}-\varphi}-\frac{u^{N}-u_{t-1}}{u_{t-1}-\varphi}\right]=x
$$

Solving for $x$ :

$$
x=\frac{\left(u_{t}-u_{t-1}\right)\left(\varphi-u^{N}\right)}{\left(u_{t}-\varphi\right)\left(u_{t-1}-\varphi\right)} .
$$

Here $u_{t}-u_{t-1}=u_{t}$; therefore, it can be written as:

$$
x=\frac{u_{t}\left(\varphi-u^{N}\right)}{\left(u_{t}-\varphi\right)\left(u_{t-1}-\varphi\right)} .
$$

Replacing the value of $x$ from Equation (8) in Equation (7):

$$
\pi_{t}^{\cdot}=\pi_{t}^{e}+\gamma\left[\frac{u_{t}\left(\varphi-u^{N}\right)}{\left(u_{t}-\varphi\right)\left(u_{t-1}-\varphi\right)}\right]-\varepsilon_{t} .
$$

Replacing the value of $u_{t}$ from Equation (6) in Equation (9):

$$
\pi_{t}^{*}=\pi_{t}^{e}+\gamma\left[\frac{\left(\varphi-u^{N}\right)}{\left(u_{t}-\varphi\right)\left(u_{t-1}-\varphi\right)}\left\{-\frac{\mu}{\alpha \beta}\left(\pi_{t}^{*}+s_{t}^{*}-\pi_{t}\right)-y_{t}^{*} \frac{\beta^{*}}{\alpha \beta}\right\}\right]-\varepsilon_{t} .
$$

We arrive at:

$$
\pi_{t}^{*}=\pi_{t}^{e}+\gamma \frac{\left(\varphi-u^{N}\right)\left(-\mu\left(\pi_{t}^{*}+s_{t}^{*}-\pi_{t}\right)-y_{t}^{*} \beta^{*}\right)}{\left(u_{t}-\varphi\right)\left(u_{t-1}-\varphi\right) \alpha \beta}-\varepsilon_{t}^{*} .
$$

The slope of the Phillips curve as derived in this paper, implies that the sacrifice ratio is not constant and the inflation and unemployment trade-off improves continuously over time. Differentiating Equation (10), the slope of Phillips curve is:

$$
\frac{\partial u_{t}}{\partial \pi_{t}^{*}}=-\frac{\left[\left(u_{t}-\varphi\right)\left(u_{t-1}-\varphi\right) \alpha \beta\right]^{2}}{\gamma\left[\left(u_{t-1}-\varphi\right) \alpha \beta\right]\left[\left(\varphi-u^{N}\right)\left\{-\mu\left(\pi_{t}^{*}+s_{t}^{*}-\pi_{t}\right)-y_{t}^{*} \beta^{*}\right\}\right]}<0 .
$$

Equation (11) reveals that an excess demand for labor would decline the unemployment rate below its minimum, which results into a rise in the wage inflation; the causality may run in both or any direction. This is in line with the structural state-dependence as suggested by in Phillips [27]. Equation (11) is also in conformity with the standard Taylor rule, which represents a negative relation between interest rate and output. However, at the same time, it makes it distinct from the contemporary studies on this subject, as the earlier studies, although take into account the non-linearity of Phillips curve, ignore the impact of openness in this relation. Openness could impact inflation through effecting unemployment in a globalized environment. Increased globalization leads to an approved employment rate thus reducing domestic inflation provided that the economy has the ex- 
port potential. However, this would depend on the value and evolution of $\varphi$ in the economy and its proportionality with the natural and current rate of unemployment.

\section{Inflation Response to Globalization}

A simple first order derivative of the domestic inflation as a function of foreign output reveals the fact that globalization places an impact on the inflation:

$$
\frac{\partial \pi_{t}^{*}}{\partial y_{t}^{*}}=-\frac{\gamma \beta^{*}\left(\varphi-u^{N}\right)}{\left(u_{t}-\varphi\right)\left(u_{t-1}-\varphi\right) \alpha \beta}<0 \text { where } \varphi>u^{N}
$$

Increased openness has a warming impact on economies with a potential to export; and consequently, this increased economic activity has a negative impact on unemployment rate. Firms finding themselves in an increasingly competitive environment would be ready to hire the skilled and the unskilled labor force to meet the global market requirements. This economic activity brings a huge labor force to the market keeping in view the effect of relaxed barriers in the goods and labor markets globally. Firstly, as per the so far literature [15] [19], huge influx in the labor market will empower the firms to decline the wages, resulting in cost pull decrease in inflation. Here the model also confirms import price channel of globalization, where cheap imports from the low cost countries help lowering the inflation in the high cost importing countries provided that $\varphi>u^{N}$. Even, ignoring this effect as it would show up in a relatively longer run, the strong demand for labor in the competitive environment raises the wages, at least the number of employed force, and by improving the purchasing power of many, it may result in demand pull inflation. However, later on once the things cool down to a stable situation, the firms will find them in a strong bargaining position, and this would lead to new scenarios.

Based on the first order derivative of inflation with respect to global output growth, we find that if the trend of unemployment rate is declining, increasing international output growth on the back of increased globalization strategy can result in a reduction of inflation rate. This is in conformity with the market sentiments as discussed above that initially the declining unemployment may lead to demand pull inflation, but later on the incentive shifts to the hands of the firms, and this result in a decline in inflation due to cost push factors. However, if the natural, current and last year's unemployment becomes even less than $\varphi$ it would result in the downward pressure on domestic inflation as well, for instance: if $\varphi>\left\{\begin{array}{l}u_{t} \\ u_{t-1} \\ u^{N}\end{array}\right\}$ resulting into $\left(u_{t}-\varphi\right)\left(u_{t-1}-\varphi\right) \alpha \beta<0$ and $\frac{\partial \pi_{t}^{\cdot}}{\partial y_{t}^{*}}>0$

Nevertheless, this does not explain the impact of increasing inflation in the rest of the world on the domestic economy. Taking a first order derivative of Equation (10) as a function of the inflation in the rest of the world reveals that globalization results in a divide in the economies based on their structures, sizes and comparative advantages. Leading back the argument to the import price channel, on the whole it leaves us with two kinds of economies: the low cost exporting economies, and the high cost importing economies. In this short run picture, the relationship between inflation in between these two kinds may be negative. As the gains in the low cost economies due to increased economic activity results into lowering of unemployment and an upward push to inflation, while on the contrary it can lower inflation in the high cost importing countries:

$$
\frac{\partial \pi_{t}^{*}}{\partial \pi_{t}^{*}}=-\frac{\gamma \mu\left(\varphi-u^{N}\right)}{\left(u_{t}-\varphi\right)\left(u_{t-1}-\varphi\right) \alpha \beta}<0 \quad \text { where } \varphi>u^{N} .
$$

However, in the long run, the improved level of employment and increasing competition in the labor and goods markets both domestically and internationally, keeps the potential to change the scenario. If the natural, current and last year's unemployment becomes even less than $\varphi$ it would result in the downward pressure on domestic inflation as well, for instance: If $\varphi>\left\{\begin{array}{l}u_{t} \\ u_{t-1} \\ u^{N}\end{array}\right\}$ resulting into $\left(u_{t}-\varphi\right)\left(u_{t-1}-\varphi\right) \alpha \beta<0$ and $\frac{\partial \pi_{t}^{*}}{\partial \pi_{t}^{*}}>0$. 


\subsection{Exchange Rate Channel}

In this case not totally, but to a greater extent this model ignores the direct impact of exchange rate movements on the back of import price channel. As increased openness would raise the imports from the low cost countries, this rising exports would depreciate the currency value in the exporting countries and this will give a two handed push to inflation in such economies. On one hand the currency depreciation results in a surge in the import prices, thus leading to a reduced import base, which puts a boosting impact on national income. On the other hand as it has already been established that increased globalization would lead to higher economic activity raising inflation:

$$
\frac{\partial \pi_{t}^{:}}{\partial s_{t}^{*}}=-\frac{\gamma \mu\left(\varphi-u^{N}\right)}{\left(u_{t}-\varphi\right)\left(u_{t-1}-\varphi\right) \alpha \beta}<0 \quad \text { where } \varphi>u^{N} .
$$

However, as discussed that this scenario is hard to persist in the long run. Two major factors are on the back of the possible diffusion of this effect. Firstly, the decreased value of local currency creates and enlarges the interest rate differential from the international market, leading to a move the gains of current account out, through the capital account. In a flexible exchange rate regime, this would overrule the earlier depreciation and resultantly a downward tracking current would move towards the general price level in the economy.

Secondly, if the natural, current and last year's unemployment becomes even less than $\varphi$ it would result in the rising the domestic inflation as a result of appreciation in the currency value, for instance: If $\varphi>\left\{\begin{array}{l}u_{t} \\ u_{t-1} \\ u^{N}\end{array}\right\}$ leading to $\left(u_{t}-\varphi\right)\left(u_{t-1}-\varphi\right) \alpha \beta<0$ and $\frac{\partial \pi_{t}^{\cdot}}{\partial s_{t}}>0$.

Although the growing economic activity, depreciating the currency due to increased exports, would also decline the level of unemployment. This huge influx of working hands in the labor market would shift the bargaining power to the firms and would put pressure on inflation due to the cost push factors.

The effect of an increase in the real exchange rate sensitivity on inflation in the backdrop of a convex Phillips curve is presented as:

$$
\frac{\partial \pi_{t}^{\cdot}}{\partial \mu}=\frac{\gamma\left(\pi_{t}-s_{t}^{*}-\pi_{t}^{*}\right)\left(\varphi-u^{N}\right)}{\left(u_{t}-\varphi\right)\left(u_{t-1}-\varphi\right) \alpha \beta}>0
$$

In Equation (10), the parameter $\mu$ puts an important condition while explaining the relationship. The value of $\mu$, being considered a positive number, reveals that the expenditures on sectoral outputs are responsive to the variations in the real exchange rate. Increasing sensitivity of output spending as a response to the exchange rate fluctuations would lead to acceleration in domestic inflation in the presence of globalization strategy, provided that the current rate of unemployment is more than the natural as well as the minimum rate of unemployment. This reflects the desired after-effects of the increased openness resulting in the enhancement of economic activity and consequently a rise in the number of jobs by the firms. Our observation is in conformity with the Daniels and VanHoose [26] [28].

However, if the natural, current and last year's unemployment becomes even less than $\varphi$ it would result in the downward pressure on domestic inflation by the increased spending on output, for instance: If $\varphi>\left\{\begin{array}{c}u_{t} \\ u_{t-1} \\ u^{N}\end{array}\right\}$, this would lead to $\left(u_{t}-\varphi\right)\left(u_{t-1}-\varphi\right) \alpha \beta<0$ and $\frac{\partial \pi_{t}^{\cdot}}{\partial \mu}<0$.

\subsection{Trade Channel (Import Price)}

Another important feature of our model, which is the epicenter of this study, is that while the propensity of the 
foreigners to import will improve the domestic unemployment, which would decline as per Phillips curve. And as it is discussed above that in the relatively longer run the domestic inflation would decline as a response to the decline in the unemployment rate as a result of the firms' behavior to reduce the wages due to the convenient availability of workers in the labor market. Here we observe this impact as follows:

$$
\frac{\partial \pi_{t}^{*}}{\partial \beta^{*}}=-\frac{\gamma y_{t}^{*}\left(\varphi-u^{N}\right)}{\left(u_{t}-\varphi\right)\left(u_{t-1}-\varphi\right) \alpha \beta}<0 .
$$

This observation is in conformity with the literature so far on this issue [3] [13] [29]. Openness will place a negative impact on inflation in the high cost importing countries, while consequently, it would lead to a rampant competition in the economics above board on the basis of comparative advantage, and would lead to a slowdown in overall inflation. Here it is noteworthy that for any variation in $\beta^{*}$ the foreign output rate would place a multiplier effect, on the domestic inflation.

However, if the natural, current and last year's unemployment goes down to a certain level, that it becomes even less than $\varphi$ it would result in the downward pressure on domestic inflation by the increased spending on output, for instance: If $\varphi>\left\{\begin{array}{c}u_{t} \\ u_{t-1} \\ u^{N}\end{array}\right\}$ This would lead to $\left(u_{t}-\varphi\right)\left(u_{t-1}-\varphi\right) \alpha \beta<0$ and $\frac{\partial \pi_{t}^{*}}{\partial \beta^{*}}>0$.

This is an implied observation that if the economies achieve a certain level of employment, it would raise the purchasing power of the society on the whole, and would raise the aggregate demand, thus raising inflation. The increasing living standard of the workers would erode the earlier benefits of the low cost imports for the economies throughout.

\section{Conclusions}

In this study we attempt to answer some of the questions regarding the impact of globalization strategy on inflation in the presence of a non-linear Phillips curve. Besides confirming the earlier observations regarding the existence of a real impact of openness on inflation, we establish that the import price channel, which is in fact the leading channel of globalization transmission mechanism, is very much operative and visible. In this regard, Daniels and VanHoose's [26] [28] observation of a greater openness has a negative impact on inflationary bias, while at the same time it has a positive relationship with sacrifice ratio raises questions. And one important question that this study answers here is that reduced trade barriers lead to a decline in inflation, even in the presence of a convex Phillips curve. This result has also a relevance to Tambakis [15] contribution where the symmetric losses with a convex Phillips curve generate positive inflation bias. However, our analysis implies that his findings could result mainly from the cross country differences in the extent of wage rigidity, structure of the labor markets. Our model predicts that in the current scenario of increased openness a non-linear symmetric loss function may still prevail, but for the policy purposes it necessitates to take into account some other important factors as well, including domestic and foreign propensities to import and the exchange rate sensitivity to inflation. In addition, the agglomeration of the international markets would result in an even more important role of exchange rate dynamics as a response to the rising international trade. Based on this consideration this factor would have a keen role in the future determination of inflation targets as well.

Our further findings are that in the presence of a convex Phillips curve any upward variation in the foreigners' propensity to import would place a downward pressure on inflation, provided that the current and the lagged rate of unemployment are less than minimum unemployment rate; however, if the minimum rate of unemployment is below the natural rate ceteris paribus, it would turn the relationship to the inverse. Our model while assessing the short run dynamics also suggests that globalization results in a complex divide among different economies, due to their sizes and structures. Once this divide is made, inflation in one part has an inverse relation with the inflation in the rest part, and though for a short time, it challenges the very existence of trade as a zero sum game anymore.

\section{References}

[1] Romer, D. (1993) Openness and Inflation: Theory and Evidence. The Quarterly Journal of Economics, 108, 869-903. 
http://dx.doi.org/10.2307/2118453

[2] Badinger, H. (2009) Globalization, the Output-Inflation Trade-Off and Inflation. European Economic Review, 53, 888907. http://dx.doi.org/10.1016/j.euroecorev.2009.03.005

[3] Ball, L. (2006) Has Globalization Changed Inflation? NBER Working Paper Series 12687.

[4] Temple, J. (2002) Openness, Inflation, and the Phillips Curve: A Puzzle. Journal of Money, Credit and Banking, 34, 450-468. http://dx.doi.org/10.1353/mcb.2002.0049

[5] Kuttner, K. and Robinson, T. (2010) Understanding the Flattening Phillips Curve. The North American Journal of Economics and Finance, 21, 110-125. http://dx.doi.org/10.1016/j.najef.2008.10.003

[6] Beaudry, P. and Doyle, M. (2000) What Happened to the Phillips Curve in the 1990s in Canada? Proceedings of Bank of Canada, Price Stability and the Long-Run Target for Monetary Policy, 51-82.

[7] Ball, L., Mankiw, N.G. and Romer, D. (1988) The New Keynesian Economics and the Output-Inflation Trade-Off. Brookings Papers on Economic Activity, 1988, 1-82. http://dx.doi.org/10.2307/2534424

[8] Bakshi, H., Khan, H. and Rudolf, B. (2004) The Phillips Curve under State Dependent Pricing. Bank of England, Working Paper, 227. http://dx.doi.org/10.2139/ssrn.641283

[9] Levin, A. and Piger, J. (2004) Is Inflation Persistence Intrinsic in Industrial Economies? Federal Reserve Bank of St. Louis, Working Paper 2002-023.

[10] Roberts, J.M. (2006) Monetary Policy and Inflation Dynamics. International Journal of Central Banking, 2, $193-230$.

[11] Williams, J.C. (2006) Inflation Persistence in an Era of Well-Anchored Inflation Expectations. FRBSF Economic Letter, No. 2006-27.

[12] Mishkin, F.S. (2007) Inflation Dynamics. International Finance, 10, 317-334. http://dx.doi.org/10.1111/j.1468-2362.2007.00205.x

[13] Syed, S.A.S. (2012) Does Greater Economic Openness Grasp the Elements of Inflation “Surprise”? New Evidence Using Panel Data Techniques. International Economics, 130, 33-59.

[14] Borio, C. and Filardo, A. (2006) Globalization and Inflation: New Cross-Country Evidence on the Global Determinants of Domestic Inflation. Working Paper 227, Bank for International Settlements, Basel.

[15] Tambakis, D. (2009) Optimal Monetary Policy with a Convex Phillips Curve. The B.E. Journal of Macroeconomics, 9, 1-25. http://dx.doi.org/10.2202/1935-1690.1649

[16] Clark, P., Laxton, D. and Rose, D. (1996) Asymmetry in the US Output-Inflation Nexus. IMF Staff Papers, 43, 216251. http://dx.doi.org/10.2307/3867358

[17] Macklem, T. (1996) Asymmetry in the Monetary Transmission Mechanism: What Can We Learn from VARS? Unpublished Manuscript, Bank of Canada Working Paper.

[18] Barro, R.J. and Gordon, D.B. (1983) Rules, Discretion and Reputation in a Model of Monetary Policy. Journal of Monetary Economics, 12, 101-121. http://dx.doi.org/10.1016/0304-3932(83)90051-x

[19] Shapiro, C. and Stiglitz, J. (1984) Equilibrium Unemployment as a Worker Discipline Device. American Economic Review, 72, 433-444.

[20] Debelle, G. and Laxton, D. (1996) Is the Phillips Curve Really a Curve? Some Evidence for Canada, the United Kingdom, and the United States. IMF Working Paper, 96/111.

[21] Laxton, D., Rose, D. and Tambakis, D. (1999) The US Phillips Curve: The Case for Asymmetry. Journal of Economic Dynamics and Control, 23, 1459-1485. http://dx.doi.org/10.1016/S0165-1889(98)00080-3

[22] Loungani, P. and Razin, A. (2005) Globalization and Disinflation: The Efficiency Channel. CEPR Discussion Paper 4895.

[23] IMF (2006) World Economic Outlook-April 2006. World Economic and Financial Surveys, Globalization and Inflation.

[24] Crowe, C. and Meade, E. (2007) The Evolution of Central Bank Governance around the World. Journal of Economic Perspectives, American Economic Association, 21, 69-90. http://dx.doi.org/10.1257/jep.21.4.69

[25] Lane, P.R. (1997) Inflation in Open Economies. Journal of International Economics, 42, 327-347. http://dx.doi.org/10.1016/S0022-1996(96)01442-0

[26] Daniels, J. and Van Hoose, H. (2006) Openness, the Sacrifice Ratio, and Inflation: Is There a Puzzle? Journal of International Money and Finance, 25, 1336-1347. http://dx.doi.org/10.1016/j.jimonfin.2006.09.005

[27] Phillips, A. (1958) The Relation between Unemployment and the Rate of Change of Money Wage Rates in the United Kingdom 1861-1957. Economica, 25, 283-299. 
[28] Daniels, J. and VanHoose, D. (2013) Exchange-Rate Pass Through, Openness, and the Sacrifice Ratio. Journal of International Money and Finance, 36, 131-150. http://dx.doi.org/10.1016/j.jimonfin.2013.03.006

[29] Rogoff, K. (2006) Impact of Globalization on Monetary Policy. Proceedings of the Symposium on the New Economic Geography: Effects and Policy Implications, Jackson Hole, 24-26 August 2006. 